\title{
Psychosocial rehabilitation: The community re-entry program (CREP) in psychiatric inpatient settings, systematic review
}

\author{
Carlos Melo-Dias \\ Nursing School of Coimbra, Scientific Unit of Mental Health and Psychiatric Nursing, Coimbra, Portugal
}

Email address:

cmelodias@esenfc.pt, cmelodias@gmail.com

To cite this article:

Carlos Melo-Dias. Psychosocial Rehabilitation: The Community Re-Entry Program (CREP) in Psychiatric Inpatient Settings, Systematic Review. American Journal of Nursing Science. Special Issue: Mental Health Care: Aspects, Challenges and Perspectives. Vol. 4, No. 2-1, 2015, pp. 51-59. doi: 10.11648/j.ajns.s.2015040201.20

\begin{abstract}
Aim: This review is an update on the research evidence supporting psychosocial rehabilitation - the Community Re-Entry Program (CREP) in psychiatric inpatient settings. Method: This review is guided by the following questions: Is the Community Re-Entry Program (CREP) effective in psychiatric inpatient settings? What are the main results and benefits of using this program in this patient population? Search strategy on Databases= MEDLINE and CINAHL (EBSCO), Cochrane Library, and SciELO, with no restriction on publication date and with the following keywords: Community Re-Entry Program OR CREP AND inpatients, in full text, in consecutive studies conducted between February, 2013, and October, 2014, in order to find all studies published that had used this program. Results: Results show that Patients with Experience of Mental Illness (PEMI) in the community re-entry program significantly improved their knowledge and performance of the skills taught in the sessions, compared to other patients. Community re-entry participants were also significantly more likely to attend their first aftercare appointment than other participants. Conclusions: The findings of the study clearly demonstrate the effectiveness of the CREP for clinical practice in psychiatric inpatient settings. From the patients' perspective, quality of life is enhanced. By learning skills to achieve their own personal relevant goals in life, individuals with serious mental disorders are empowered to function more autonomously from mental health professionals. Our general conclusion is that the Community Re-Entry Program for psychiatric inpatients is effective in teaching them about their illness and symptoms as well as improving their ability to make and keep appointments. Further studies should address the dissemination of the CREP in European countries, including a Portuguese Nursing version, as a way to increase the likelihood that the individual will be successful with skills training within the treatment and care areas of psychiatric and mental health nurses.
\end{abstract}

Keywords: Community Re-Entry Program, Psychosocial Rehabilitation, Nursing, Schizophrenia

\section{Introduction}

As in other fields, prevention in Psychiatry involves different levels - primary, prevention, secondary, and tertiary - in a care continuum which aims at health promotion [1].

In the past, psychiatric rehabilitation was only used upon the "completion" of the pharmacological treatment or as an alternative when the treatment failed [2].

Although there are no conceptual or operational differences between "treatment" and "rehabilitation", the two terms have inadvertently been separated, because researchers and practitioners have focused their work in different realms [3].The tertiary level of prevention essentially translates into the reduction of diseases, disability or residual impairment [1].
The social competence, which is impaired in these subjects, includes those behaviors that provide interpersonal communication and clear expressed emotions and needs, aiming at reaching the desired individual goals.

One of the most empirically supported approaches for understanding social functioning and dysfunction in illness is the social skills model [4].

This model postulates that social competence is based on a set of component skills: 1- Social Perception or Receiving Skills; 2- Social Cognition or Processing Skills; 3- Behavioral Response or Expressive Skills [4,5].

Social perception is the ability to accurately read or decode social inputs. This includes accurate detection of affect cues, such as facial expressions and nuances of voice, gesture, and 
body posture, as well as verbal content and contextual information. Social cognition involves effective analysis of the social stimulus, integration of current information and historical information, and decision planning. Behavioral response or expressive skills include the ability to generate effective verbal content, to speak with appropriate paralinguistic characteristics, and to use suitable nonverbal behaviors, such as facial expressions, gestures, and posture [ 4 p. 377].

Over the last decade, Social Skills Training (SST) has emerged as an important intervention for enhancing social functioning and reducing the risk of symptom relapses in patients with schizophrenia spectrum and major affective disorders [6].

Several authors have defined psychosocial rehabilitation [1,7-12] and, nowadays, we must acknowledge it as a concept, a body of knowledge with ways of organizing services and methods subject to empirical validation, as may be observed in the following definition.

The psychosocial rehabilitation process have as major principle to provide people who have mental disabilities with the opportunity to reach their full potential for independent functioning in the community, helping them to perform physical emotional, and intellectual skills with the necessary autonomy, at the highest possible level of well-being and with the least possible help of health care professionals [13].

This systematic training is focused on enhancing both verbal and non-verbal behaviors and developing more accurate social perception and judgment, within the scope of Bandura's Social Learning Theory and the scope of Skinner's Operant Conditioning, techniques that have been tried and tested effective for the full range of human learning and behavior therapy [10].

Complex behaviors are broken down into a smaller set of constituent behavioral elements, which are organized into a hierarchy of responses and then trained using various core behavioral techniques $[8,14]$. These techniques include problem or skill specification, setting clear expectations with specific instructions, didactic instruction, coaching, using modeling or vicarious identification, role-play or behavioral rehearsal, generalization training, homework, and offering abundant positive feedback or reinforcement for small improvements in social behavior $[8,10]$.

Although SST content will differ based on the counterpart, time, circumstance, and so on, the methods of training are similar. Integrating studies from various investigators, we acknowledge that training methods of social skills are divided into five parts: explanation, demonstration, role-play, feedback and social enhancement, and a homework exercise. The leader develops simple circumstances and explains the problem that may be encountered and the skill to deal with it in advance of the training [15]. "This training uses video and audio media or a blackboard to assist oral expression, to help the patients see the action and learn. Demonstration is used to show the patient the proper response to each situation to indicate proper behavior. A patient and therapist are then selected to practice, or patients participate in a role-play and receive feedback. Feedback should be concrete and positive and give encouragement based on the patient's practical behavior; feedback given immediately after the role-play has a greater effect. Regardless of how well the patient interacts in the group, the patient must exercise this skill and routinely apply it in daily life" [15 p.229].

However, the well-known chronic scarcity of resources associated with the difficulties of creating a network of community services is what results from unclear mental health policies that show dissociative tendencies derived from lack of articulation and coordination of services and partners [1].

For this reason, it is understandable that the WHO organization proposes that staff currently working in mental hospitals need training to adopt more recovery-focused treatments so that they can prepare people for hospital discharge [16].

SST is targeted rather than broad, and it is a highly structured approach that involves systematically teaching patients specific behaviors that are critical for success in social interactions [17].

This type of clinical rehabilitation in the acute phase aims at reducing over-stimulating or stressful relationships, environments, or life events and at promoting relaxation or reduced arousal through simple, clear, coherent communications and expectations; a structured and predictable environment; low performance requirements; and tolerant, non-demanding, supportive relationships with the psychiatrist and other members of the treatment team [17].

At this phase, the main therapeutic challenge is to select and "titrate" the doses of both pharmacological and psychosocial interventions in accordance with the symptoms and socio-behavioral functioning of the patient [17].

Therefore, since SST aims at improving our communication of feelings and needs, as well as the quality of our relationships, everyone can benefit from this approach [10], regardless of gender, age, culture, being hospitalized or living in community [1].

However, as we have seen, the goals must be tailored to fit the priorities and personal preferences of each individual and the methods must also be modified somewhat to ensure that the learning disabilities present can be overcome [10]. Among the common goals that people have achieved in SST, making friends, starting conversations and getting discharged from the hospital are the core and most meaningful ones.

A large body of research supports the efficacy of SST for serious and persistent mental disorders, in particular schizophrenia and depression. Despite the fact that one reference out of the nine randomized trials that concluded that SST (SST) was not substantially effective when comparing SST to all other interventions [4], all other reviews make evidence that the efficacy of STT has been accumulated for the following outcome dimensions: acquisition, durability, and utilization of the skills in real life; improvements in social functioning; reductions in relapse readmission rates; and enhanced quality of life [4, 8, 14, 18-24].

This evidence is also supported for inpatient settings $[8,14$, $18,20,22]$. 
Assuming that evidence supports SST in psychiatric inpatients, and that our interest focuses on modular SST, specifically the Community Re-Entry Program of the Social and Independent Living Skills Program - University of California, Los Angeles (UCLA)(25), this review is guided by the following questions:

- Is the Community Re-Entry Program (CREP) effective in adult acute psychiatric inpatients? And

- What are the main results and benefits of using this program in acute psychiatric inpatients?

\section{The Intervention Program}

The Community Re-Entry Program (CREP) is the fifth training module of the Social and Independent Living Skills Program [25], developed by the Intervention Research Centre for Major Mental Illness at the University of California, Los Angeles [26], and has been explicitly designed for use in rapid turnover, short-stay inpatient facilities [27].

The goal of the Community Re-Entry Module is to teach participants the skills to collaborate in designing and following through with their treatment plans after a period of inpatient or transitional care. Participants can use these skills to: smoothly transition among the various services offered by their local mental health providers; reduce the risk of relapse or readmission by following through with their aftercare treatment plans; collaborate with their physicians to identify the medication regimen that will help them make the transition to aftercare [27].

Table 1. Topics covered in the 16 sessions of the Community Re-Entry Program.

\begin{tabular}{ll}
\hline Session & Topic \\
\hline 1. & Introduction to the Community Re-Entry Program \\
2. & Symptoms of disabling mental disorders \\
3. & Determining discharge readiness \\
4. & Community Re-Entry (discharge) planning \\
5. & Connecting with the community \\
6. & Coping with stress in the community \\
7. & Planning a daily schedule \\
8. & Making and keeping appointments \\
9. & How medications work to prevent relapse \\
10. & Evaluating effects of medication \\
11. & Solving medication problems \\
12. & Solving medication side effects \\
13. & Identifying warning signs of relapse \\
14. & Keeping track of warning signs \\
15. & Developing an emergency relapse prevention plan \\
16. & Bringing your emergency plan to the community \\
\hline
\end{tabular}

Adapted (28)

The program teaches participants how to design and follow through with an aftercare treatment plan, which addresses discharge planning, connecting with community, coping, planning, and medication awareness.

The program consists of 16 training sessions each 45 minutes long, divided into two eight-session sections [26]. Sessions can be held separately, thus limiting the focus to discharge planning, and twice a day (e.g. morning and afternoon) [27].

These 16 sessions (see table 1) were selected because they were described by the authors of the community re-entry program as particularly relevant for patients who are preparing for discharge from the hospital [26], and also because this program is formatted for continuous implementation, with participants "dropping in" as their schedules permit [11].

In these sessions, the skills are taught using seven learning activities. These seven steps are used regardless of the content (see table 2).

Table 2. Seven learning activities from the Community Re-Entry Program.

\begin{tabular}{|c|c|}
\hline Activity & Content \\
\hline Introduction & $\begin{array}{l}\text { Participants are provided with a rationale and } \\
\text { motivation to learn the skills }\end{array}$ \\
\hline $\begin{array}{l}\text { Videotape with } \\
\text { questions and } \\
\text { answers }\end{array}$ & $\begin{array}{l}\text { A videotaped demonstration of the skills has periodic } \\
\text { stops to allow the trainer to ask prepared questions } \\
\text { designed to assess participants' understanding of the } \\
\text { demonstration }\end{array}$ \\
\hline $\begin{array}{l}\text { Behavioral } \\
\text { rehearsal }\end{array}$ & $\begin{array}{l}\text { Participants role play the skills, and the trainer uses a } \\
\text { checklist to assess the accuracy of the role plays }\end{array}$ \\
\hline $\begin{array}{l}\text { Solving resource } \\
\text { management } \\
\text { problems }\end{array}$ & $\begin{array}{l}\text { Participants identify the resources necessary to carry } \\
\text { out the skills by considering the steps necessary to } \\
\text { obtain the resources }\end{array}$ \\
\hline $\begin{array}{l}\text { Solving outcome } \\
\text { problems }\end{array}$ & $\begin{array}{l}\text { Participants learn how to solve unexpected problems } \\
\text { by identifying potential obstacles, generating } \\
\text { alternative solutions, evaluating them, and selecting } \\
\text { the most effective one }\end{array}$ \\
\hline In-vivo exercises & $\begin{array}{l}\text { The trainer accompanies participants "in the field" to } \\
\text { assess performance of the skills and provide } \\
\text { corrective feedback if necessary }\end{array}$ \\
\hline $\begin{array}{l}\text { Homework } \\
\text { assignments }\end{array}$ & $\begin{array}{l}\text { Individuals complete homework assignments in their } \\
\text { natural environment and provide "permanent } \\
\text { product" evidence of completion }\end{array}$ \\
\hline
\end{tabular}

Adapted (26)

\section{Methodology}

This review is guided by the following questions: - Is the Community Re-Entry Program (CREP) effective in adult acute psychiatric inpatients? And What are the main results and benefits of using this program in acute psychiatric inpatients?

Search strategy on Databases $=$ MEDLINE and CINAHL (EBSCO), Cochrane Library, and SciELO, with no restriction on publication date and with the following keywords: Community Re-Entry Program OR CREP AND inpatients, in full text, in consecutive studies conducted between February, 2013, and October, 2014, in order to find all studies published that had used this program (see figure 1).

The following organizational research and registration method - PISCOS - was used [29, 30]: Participant = psychiatric patient; Intervention $=$ CREP; Setting $=$ hospital; Comparison $=$ with any other intervention; Outcomes = acquisition of knowledge and skills; Study design = any quantitative study.

We also checked the references in the obtained articles to ensure that other relevant articles that had not been identified with the initial searches were included. 
The following inclusion criteria were used to refine the search: the subjects must be acute psychiatric inpatients and the intervention must be the Community Re-Entry Program, duly adapted to this acute psychiatric inpatient setting.

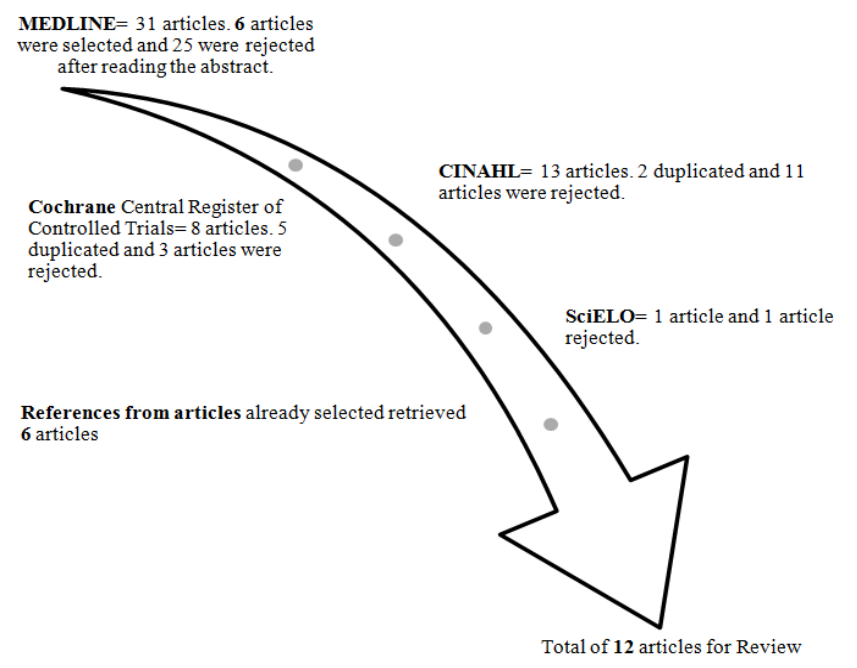

Figure 1. Flow diagram of study selection process.

\section{Results}

After applying these intentionally narrower criteria to the search strategy, 12 studies were selected:

S1 - Smith, Hull, Goodman, Anthony \&Kentros (1996) Learning social skills in psychotic patients: gender effects [31];

S2 - Smith, Hull, MacKain, Wallace, Rattenni, Goodman, Anthony \&Kentros (1996) Training hospitalized patients with schizophrenia in community reintegration skills [32];

S3 - Kopelowicz, Zarate \& Wallace (1997) Successful transition from the hospital to the community [33];

S4 - Kopelowicz, Wallace \& Zarate (1998) Teaching
Psychiatric Inpatients to Re-Enter the Community: A Brief Method of Improving the Continuity of Care [26];

S5 - Wirshing, Rossotto, Watson, Benveniste, Marder, Liberman, Wirshing \&Mintz (1998) The Community Re-Entry Program for Schizophrenia Patients [34];

S6 - Smith, Hull, Romanelli, Fertuck\& Weiss (1999) Symptoms and Neurocognition as Rate Limiters in Skills Training for Psychotic Patients [35];

S7 - Wirshing, Wirshing, Gonzalez \&Rossoto (2000) The Community Re-Entry Program for Schizophrenia: Preliminary Findings [36];

S8 - Naoki, Nobuo \& Emi (2003) Randomized controlled trial on effectiveness of the community re-entry program to inpatients with schizophrenia spectrum disorder, centering around acquisition of illness self-management knowledge [37];

S9 - Rossotto, Wirshing \& Liberman (2004) Enhancing Treatment Adherence among Persons With Schizophrenia by Teaching Community Reintegration Skills [38];

S10 - Wirshing, Guzik, Zorick, Pierre, Resnick, Goldstein, Wirshing (2006) Community re-entry program training module for schizophrenic inpatients improves treatment outcomes [39];

S11 - Xiang, Weng, Li, Gao, Chen, Xie, Chang, Tang \&Ungvari (2006) Training patients with schizophrenia with the community re-entry module [40];

S12 - Sato, Ikebuchi, Anzai\& Inoue (2012) Effects of psychosocial program for preparing long-term hospitalized patients with schizophrenia for discharge from hospital: randomized controlled trial [41];

Table 3 presents a detailed description of the studies to increase discussion and show the similarities and differences between them.

Table 3. Outcomes from Studies using the Community Re-Entry Program in Inpatient Psychiatric Settings.

\begin{tabular}{|c|c|c|c|c|c|}
\hline & Authors & Participant & Intervention & Setting & $\begin{array}{l}\text { Comparison/Ass } \\
\text { essment }\end{array}$ \\
\hline S1 & $\begin{array}{l}\text { Smith et al. } \\
\text { (1996a) } \\
\text { [USA] }\end{array}$ & $\begin{array}{l}32 \text { patients } \\
\text { with } \\
\text { schizophrenia } \\
\text { or } \\
\text { schizoaffectiv } \\
\text { e disorder. }\end{array}$ & $\begin{array}{l}\text { Community } \\
\text { Re-Entry Program } \\
\text { (CREP) } 16 \text { Sessions }\end{array}$ & Hospital & $\begin{array}{l}\text { Symptoms and From admission to discharge, symptoms } \\
\text { skill levels. diminished and skill levels increased to a } \\
\text { Pre-training and statistically significant degree. Women and Cohort Study } \\
\text { posst-training, patients with high levels of participation had } \\
\text { without follow-up. greater rates of skill acquisition. }\end{array}$ \\
\hline S2 & $\begin{array}{l}\text { Smith et al. } \\
\text { (1996b) } \\
\text { [USA] }\end{array}$ & $\begin{array}{l}44 \text { patients } \\
\text { with chronic } \\
\text { psychotic } \\
\text { disorders } \\
\text { completed and } \\
\text { attended the } \\
\text { program. } \\
\text { Schizophrenia } \\
(55 \%) \text { and } \\
\text { other } \\
\text { psychotic } \\
\text { disorders } \\
(45 \%) \text {. }\end{array}$ & $\begin{array}{l}\text { CREP } 16 \text { daily } \\
\text { sessions }\end{array}$ & Hospital & 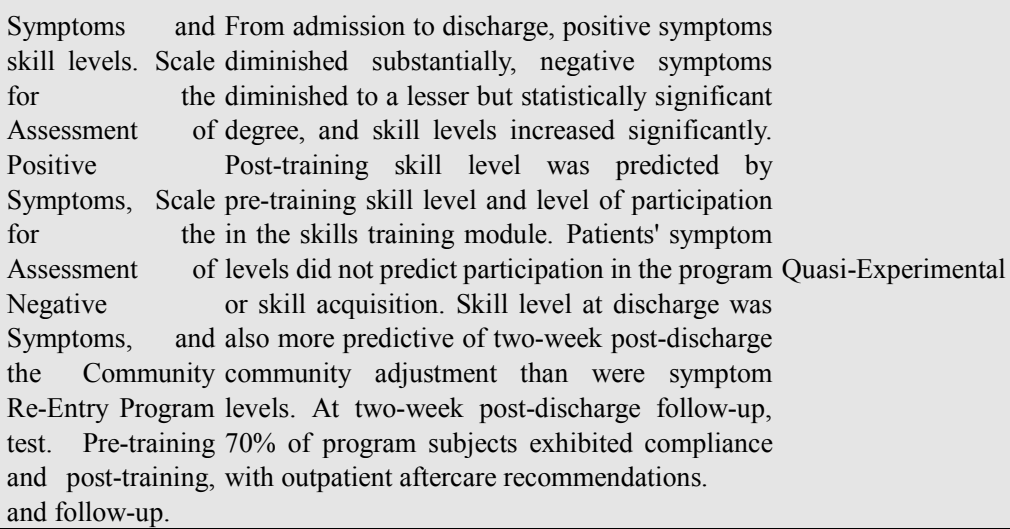 \\
\hline
\end{tabular}




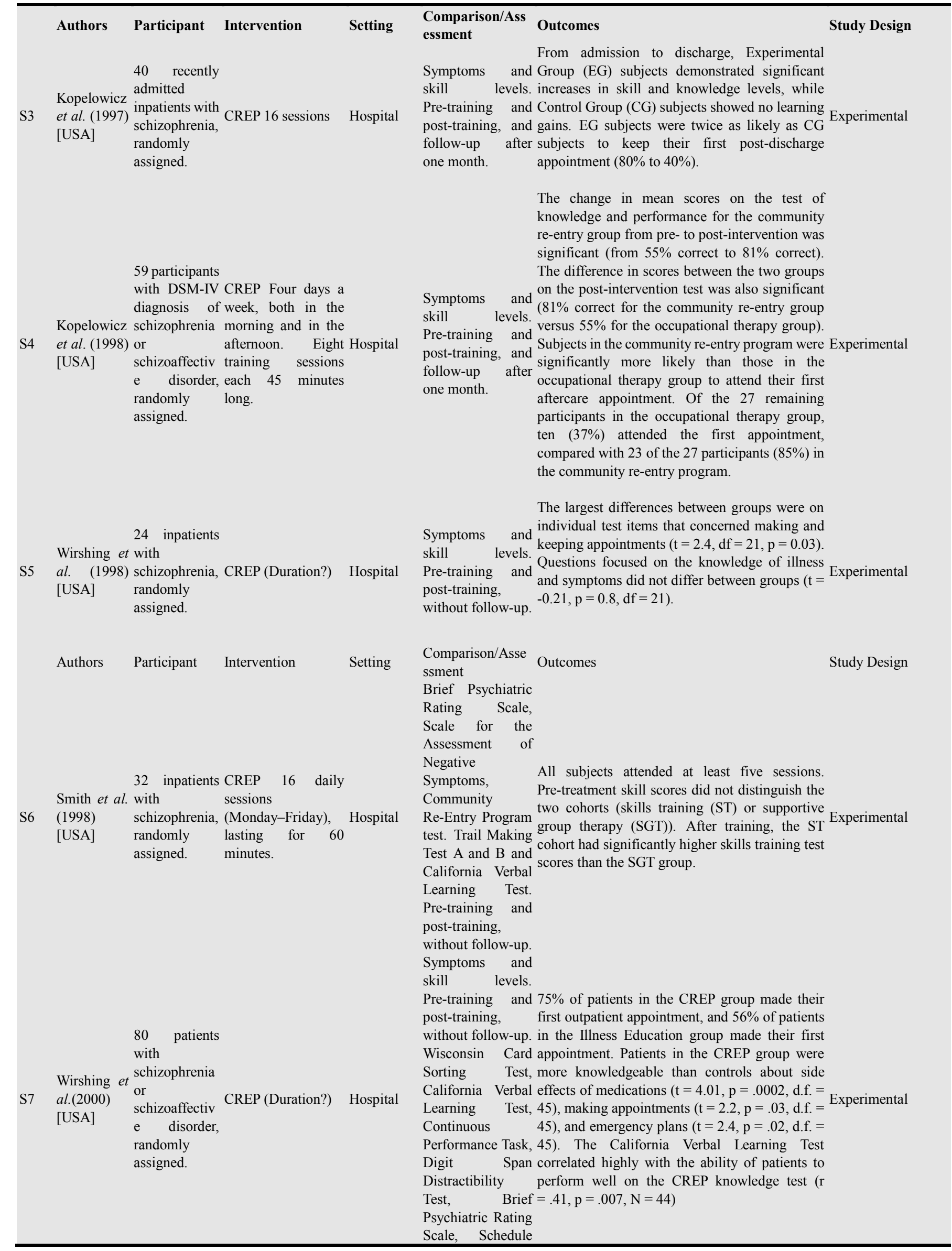




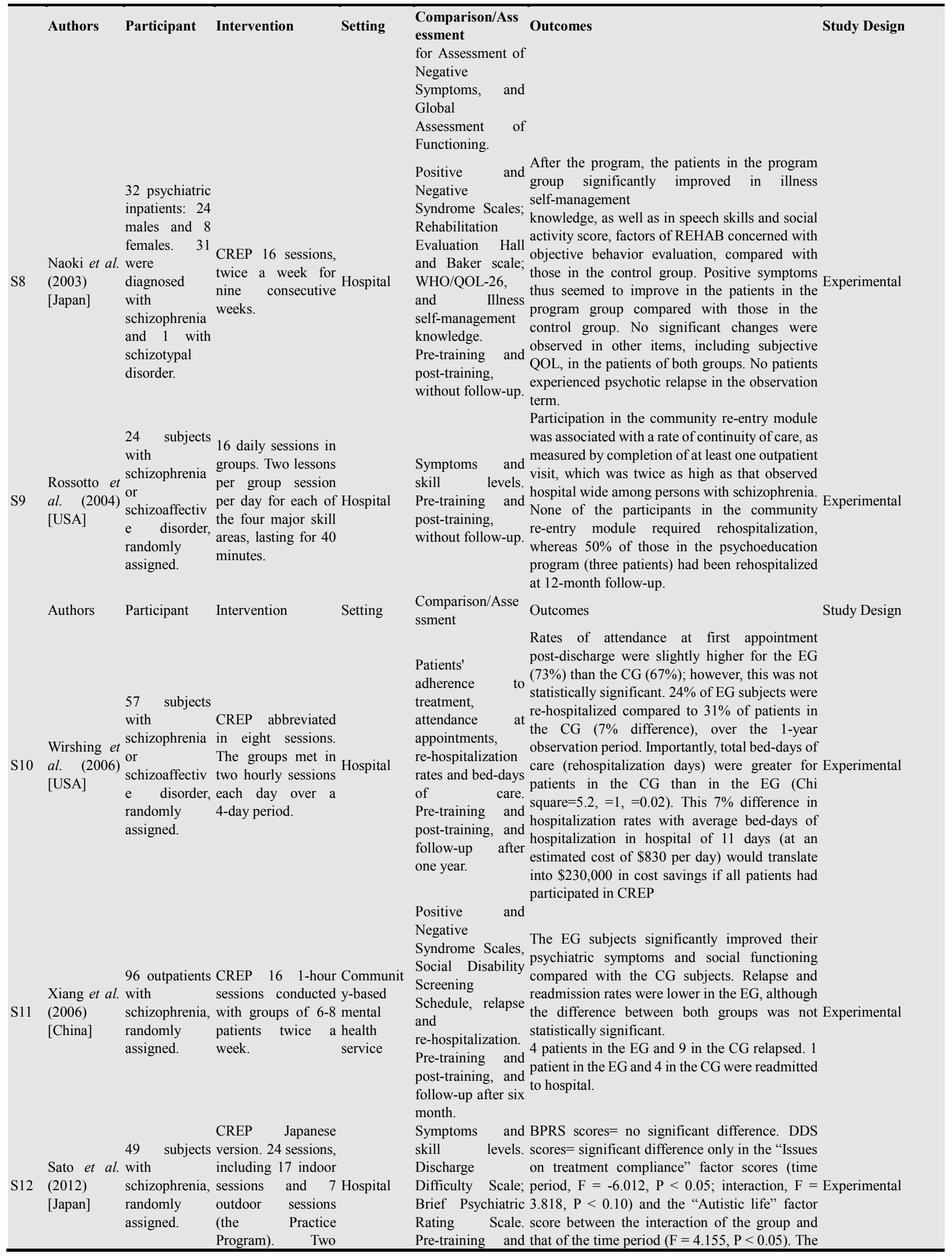




\begin{tabular}{|c|c|c|c|c|c|}
\hline Authors & Participant & $\begin{array}{l}\text { Intervention } \\
\text { sessions per week, } \\
\text { with } 60-90 \text { min } \\
\text { each. }\end{array}$ & Setting & $\begin{array}{l}\text { Comparison/Ass } \\
\text { essment } \\
\text { post-training, } \\
\text { without follow-up. }\end{array}$ & $\begin{array}{l}\text { Outcomes } \\
\text { simple main effects of the time period in the } \\
\text { participation group were significant }(\mathrm{t}=12.360, \mathrm{P} \\
<0.01 \text { and }(\mathrm{t}=4.490, \mathrm{P}<0.05 \text {, respectively). } \\
\text { Knowledge test total score }=\text { mean of } 4.52 \text { in the } \\
\text { CG subjects and mean of } 9.88 \text { in the EG subjects. }\end{array}$ \\
\hline
\end{tabular}

\section{Discussion}

\subsection{Participants [Patients with Experience of Mental Illness (PEMI)]}

All sample studies included participants with only schizophrenia or with schizophrenia and schizoaffective disorders in psychiatric inpatient wards (except S11 in which participants came from a community-based mental health service). With a total of 549 participants, the 12 research studies included a considerably significant number of participants, which could be a positive criterion for clinical evidence. The mean number of participants reached 47.42, within a maximum of 96 and a minimum of 24 participants.

There was scarce information on gender participation and contribution, as well as the losses resulting from the studies, thus such aspects cannot be reported.

\subsection{Skills Training Program}

Since the Community Re-Entry Program (CREP) was an inclusion criteria, all studies used CREP as an intervention and, despite the limitation of some missing values, the time schedule was somewhat different between them: seven (S1,S2, S3, S6, S8, S9, and S11) applied the CREP in 16 sessions, two (S4 and S10) applied it in eight sessions, and only one (S12, the Japanese version) applied it in 24 sessions (including 17 indoor sessions and seven outdoor sessions). Despite the missing data, the average time for each session was between 40 to 60 minutes.

\subsection{Study Design}

Six studies used an experimental or quasi-experimental design and all subjects were randomly assigned to the experimental or control groups. The other two studies used a within-group design.

Ten studies had experimental design, whereas S2 was a quasi-experimental study and S1 a cohort study. Among these, more than half (seven studies) had no follow-up assessment and the five studies with follow-up performed it at one, six, and twelve months.

In general, all but one study (S10) assessed psychiatric symptoms and all but two studies (S10 and S11) assessed knowledge and skill levels, although almost all studies don't publish all the results.

Despite the fact that most studies focused on assessing knowledge and skill levels, with the exception of S4, there were no reports of attempts to blind the assessment of outcomes. Furthermore, it seems that in all studies, the person delivering the intervention was also responsible for measuring the outcomes. This clearly minimized the cost, but could also decrease performance and detection biases.

As previously seen, only less than half of the studies included follow-up information, thus some doubts may be raised concerning the durability of outcomes.

It was also impossible to perform a meaningful meta-analysis given the diversity of assessment instruments, but also and especially given the gap in reporting several values/data.

In spite of the reported inaccuracies, the registered outcomes have clinical and psychosocial meaning, are evidence-based and present meaningful use in practice, as may be seen in the following paragraphs.

\subsection{Outcomes}

First, the limitations: one consistent weakness was that none of the studies included a medication treatment control (and most of them did not even mention medication). The other was the diverse and usually missing data in the original studies, allowing only for a descriptive presentation of data.

Second, the positive outcomes and significant evidence:

Almost all studies emphasized the positive outcomes of the CREP intervention in this inpatient setting, particularly this anchor statement: from admission to discharge, symptoms diminished and skill levels increased to a statistically significant degree.

In studies with follow-up, the experimental group participants exhibited more compliance as outpatients and were also more likely to attend their first post-discharge appointment.

The post-training skill level was predicted by a pre-training skill level and level of participation in the skills training module and the ability to attend the first aftercare appointment. Thus, EG participants were also significantly more likely to attend their first aftercare appointment than CG participants, being twice more compliant with outpatient aftercare recommendations, in mean values of $80 \%$ in EG to $40 \%$ in CG.

Results on relapse and readmission were diverse, for example, some studies show a better response with 4 participants relapsing and readmitted to hospital in EG for 9 participants in the $\mathrm{CG}$, and another with 0 participants in the EG and 3 participants in the CG relapsing and readmitted to hospital, respectively. Unfortunately, we cannot assess the influence of this intervention on relapse and/or readmission given the missing values, which raises difficulties in analyses and comparisons.

Only S10 presented an economic reflection; however, this type of inferences are clearly relevant. Their finding that $24 \%$ of EG subjects had been re-hospitalized compared to $31 \%$ of patients in the CG $(7 \%$ difference $)$, over the 1 -year 
observation with average bed-days of hospitalization of 11 days (at an estimated cost of $\$ 830$ per day) would translate into $\$ 230,000$ in cost savings if all patients in that inpatient setting had participated in the CREP.

\section{Conclusion}

The findings of the present review demonstrate the effectiveness of the CREP in psychiatric inpatient settings and have important implications for clinical practice.

Compared to control subjects, the patients with experience of Mental Illness (PEMI), participants in the CREP program exhibited significantly greater knowledge and better performance of targeted skills after treatment and were more likely to attend their first community aftercare appointment (follow-up assessment).

From the patients' perspective, quality of life is enhanced. They are provided with a sense of personal effectiveness and a wider range of realistic choices among social, vocational, recreational, and community living situations which they can adequately cope with and enjoy. By learning skills to achieve their own personal relevant goals in life, individuals with serious mental disorders are empowered to function more autonomously from mental health professionals [10].

Not only can patients learn relatively complex material during a brief typical inpatient stay despite the acuteness of their illnesses, but they can also meaningfully improve the continuity of their own care by participating in a brief and highly structured training program. In addition, this program fits well within the time and staffing constraints of typical inpatient facilities [26].

Our general conclusion is that the Community Re-Entry Program for psychiatric inpatients is effective in teaching them about their illness and symptoms as well as improving their ability to make and keep appointments.

Unfortunately, many patients with schizophrenia and depression lack the level of cognitive, affective and social competence to consistently follow-through and get their needs met; therefore, taking into account the patient's cultural background is a significant factor in determining the treatment plan and how skills training will be conducted [10]. Further studies should address the dissemination of the CREP in European countries, including a Portuguese Nursing version, as a way to increase the likelihood that the individual will be successful with skills training. We should assume that culture is more than just the language spoken, and that it will play an important role in determining the outcome expectancies of treatment and care in psychiatric and mental health nurses.

Since effective interventions tend to be domain-specific, specific and sensitive interventions such as the Community Re-Entry Program should also target a different population in psychiatric inpatient settings, such as depressed patients. This would likely be more productive in clarifying and ensuring the CREP wide effectiveness.

As previously seen, we may infer that these are key interventions for Nurses and their clients because they directly target relapse and readmission, thus identifying and focusing on the core areas of functioning such as interpersonal relationship, coping with disease and treatments, burden of symptoms, cognitive functioning, and generalization and social integration.

\section{References}

[1] Santos MJH. Esquizofrenia: perspectivas actuais de reabilitação psicossocial. Psicologia. 2000, Vols. XIV:91-109.

[2] Hirdes A \& Kantorski LP. Reabilitação psicossocial: objetivos, princípios e valores. Revista de Enfermagem da UERJ. 2004, Vols. 12(2):217-221.

[3] Kopelowicz A \& Liberman RP.Integrating Treatment with Rehabilitation for Persons with Major Mental Illnesses. Psychiatric Services. November, 2003, Vols. 54(11):14911498.

[4] Bellack AS. Skills Training for people with severe mental illness, . Psychiatric Rehabilitation Journa. 2004, Vol. 27(4).

[5] Coelho CM, Silva CF, Silvério JMA \& Palha AP,. Treino de habilidades sociais aplicado a pessoas com esquizofrenia. Psiquiatria Clínica. 2002, Vols. 23(3):205-215.

[6] Mueser KT, Levine S, Bellack AS, Douglas MS \& Brady EU,.Social skills training for acute psychiatric inpatients. Hospital and Community Psychiatry. 1990, Vols. 41:1249-1251.

[7] WHO - World Health Organization.Innovative Approaches in Mental Health Care - Psychosocial Interventions and Case Management. Geneva : Division of Mental Health - WHO, 1992.

[8] Scott JE, Dixon LB,. Psychological Interventions for Schizophrenia. Schizophrenia Bulletin. 1995, Vol. 21(4).

[9] Segrin C. Social skills deficits associated with depression. Clinical Psychology Review. April, 2000, Vols. 20(3):379-403.

[10] Liberman RP \& Martin T,. Social Skills Training. Psychiatric REHAB Program. [Online] 2002. [citation: 09-05-2010.] http://www.bhrm.org/guidelines/Liberman\%20social\%20skills $\% 20$ training.

[11] Kopelowicz A, Liberman RP \& Wallace CJ,. Psychiatric Rehabilitation for Schizophrenia. International Journal of Psychology and Psychological Therapy. 2003, Vols. 3(2):283-298.

[12] Silverstein SM, Wallace CJ \& Schenkel LS,. The Micro-Module Learning Tests: Work-Sample Assessments of Responsiveness to Skills Training. Schizophrenia Bulletin. 2005, Vols. 31(1):73-83.

[13] Melo-Dias C, Rosa A \& Pinto A,. Atividades de Ocupação Terapêutica - intervenções de enfermagem estruturadas em reabilitação psicossocial. Revista Portuguesa de Enfermagem de Saúde Mental. 2014, Vols. 11:15-23.

[14] Heinssen RK, Liberman RP \& Kopelowicz A,.Psychosocial skills training for schizophrenia: Lessons from the laboratory. Schizophrenia Bulletin. 2000, Vol. 26(1):21.

[15] Chien H, Ku C, Lu R, Chu H, Tao Y \& Chou K,. Effects of social skills training on improving social skills of patents with schizophrenia. Archive of Psychiatric Nursing. October, 2003, Vols. 17(5):228-236. 
[16] WHO - World Health Organization.Human resources and training for mental health. WHO European Ministerial Conference on Mental Health. Helsinki : WHO, 2004.

[17] APA - American Psychiatric Association.Practice Guideline for the Treatment of Patients with Schizophrenia. s.l. : American Psychiatric Association, 2004.

[18] Brady JP. Social skills training for psychiatric patients, II: Clinical outcome studies. American Journal Psychiatry. 1984, Vols. 141:491-498.

[19] Benton MK \& Schroeder HE. Social Skills Training with Schizophrenics: A Meta-Analytic Evaluation. Journal of Consulting and Clinical Psychology. December, 1990, Vols. 58(6)741-747.

[20] Corrigan PW. Social skills training in adult psychiatric populations: A meta-analysis. Journal of Behavior Therapy and Experimental Psychiatry. 1991, Vols. 22:203-210.

[21] Penn DL \& Mueser KT. Research update on the psychosocial treatment of schizophrenia. American Journal Psychiatry. 1996, Vols. 153:607-617.

[22] Dilk MN \& Bond GR. Meta-Analytic Evaluation of Skills Training Research for Individuals with Severe Mental Illness. Journal of Consulting and Clinical Psychology. December, 1996, Vols. 64(6):1337-1346.

[23] Lockwood C, Page T, Conroy-Hiller T,. Effectiveness of individual therapy and group therapy in the treatment of schizophrenia. Joanna Briggs Institute - JBI REPORTS. 2004, Vols. 2:309-338.

[24] Bustillo JR, Lauriello J, Horan WP \& Keith SJ,. The Psychosocial Treatment of Schizophrenia: An Update. American Journal Psychiatry. February, 2001, Vols. 158:163-175.

[25] Liberman RP, Wallace CJ, Blackwell G, Eckman TA, Vaccaro JV \& Keuehnel TG,. Innovations in skills training for the seriously mental ill: the UCLA Social and Independent Living Skills Modules. Innov. Res. 1993, Vols. 2:43-60.

[26] Kopelowicz A, Wallace CJ \& Zarate R,. Teaching Psychiatric Inpatients to Re-Enter the Community: A Brief Method of Improving the Continuity of Care. Psychiatric Services. October, 1998, Vols. 49(10):1313-1316.

[27] PRC - Psychiatric Rehabilitation Consultants. Modules (for training social and independent living skills). [Online] [citation: 12-9-2012.] www.psychrehab.com.

[28] Mackain SJ, Smith TE, Wallace CW \& Kopelowicz A, Evaluation of a community re-entry program. International Review of Psychiatry. 1998, Vols. 10:76-83.

[29] CRD - Centre for Reviews and Dissemination.Systematic Reviews - CRD's guidance for undertaking reviews in health care. York : CRD, University of York, 2009. Available 07-01-2010,

http://www.york.ac.uk/inst/crd/pdf/Systematic_Reviews.pdf. 978-1-900640-47-3.

[30] Melo-Dias C \& Lopes M. RSL Operacionalizada. Revista Nursing. Julho, 2011, Vols. 271(23):21-27.
[31] Smith TE, Hull JW, Goodman M, Anthony DT \& Kentros, MK, Learning social skills in psychotic patients: gender effects. Biological Psychiatry. April, 1996, Vol. 39(7):552, (congress abstract).

[32] Smith TE, Hull JW, MacKain SJ, Wallace CJ, Rattenni LA, Goodman M, Anthony DT \& Kentros MK,. Training hospitalized patients with schizophrenia in community reintegration skills. Psychiatry Services. October, 1996, Vols. 47(10):1099-103.

[33] Kopelowicz A, Zarate R \& Wallace CJ,. Successful Transition from the Hospital to the Community. Schizophrenia Research (Special Issue). 1997, The VIth International Congress on Schizophrenia Research, Colorado Springs, Colorado, USA, April.

[34] The community re-entry for schizophrenia patients. Wirshing, DA, Rossotto, EH, Watson JB, Benveniste RE, Marder SR, Liberman RP, Wirshing WC, Mintz J. Toronto, Canada : American Psychiatric Association, 1998. Annual Meeting on the American Psychiatric Association. New Research Programs and Abstracts, NR540:213.

[35] Smith TE, Hull JW, Romanelli S, Fertuck E \& Weiss KA, Symptoms and Neurocognition as Rate Limiters in Skills Training for Psychotic Patients. American Journal of Psychiatry. 1999, Vols. 156:1817-1818.

[36] Wirshing D, Wirshing WC, Gonzalez L \& Rossoto E,. The Community Re-Entry Program for Schizophrenia: Preliminary Findings (congress abstract). [Online] 2000. [citation: 1-3-2013.]

http://www.psych.org/edu/other_res/lib_archives/archives/mee tings/2000ips.cfm.

[37] Naoki K, Nobuo A, Emi I,.Randomized controlled trial on effectiveness of the community re-entry program to inpatients with schizophrenia spectrum disorder, centering around acquisition of illness self-management knowledge. Seishin Shinkeigaku Zasshi. 2003, Vols. 105(12):1514-31. [Article in Japanese].

[38] Rossotto E, Wirshing DA \& Liberman RP,. Enhancing Treatment Adherence Among Persons with Schizophrenia by Teaching Community Reintegration Skills. Psychiatric Services. January, 2004, Vol. 55(1).

[39] Wirshing DA, Guzik LH, Zorick TS, Pierre JM, Resnick SA, Goldstein D, Wirshing WC,. Community re-entry program training module for schizophrenic inpatients improves treatment outcomes. Schizophrenia Research. 2006, Vols. $87: 338-339$.

[40] Xiang Y, Weng Y, Li W, Gao L, Chen G, Xie L, Chang Y, Tang W-K \& Ungvari GS,. Training patients with schizophrenia with the community re-entry module. Soc Psychiatry Psychiatr Epidemiol. 2006, Vols. 41:464-469.

[41] Sato S, Ikebuchi E, Anzai N \& Inoue S,. Effects of psychosocial program for preparing long-term hospitalized patients with schizophrenia for discharge from hospital: randomized controlled trial. Psychiatry and Clinical Neurosciences. 2012, Vols. 66: 474-481. 